\title{
Thermal Behavior of Polytriazole Films: A Thermal Analysis Study
}

\author{
B. GEBBEN, M. H. V. MULDER, and C. A. SMOLDERS, University \\ of Twente, Department of Chemical Technology, P.O. Box 217, 7500 \\ $A E$ Enschede, The Netherlands
}

\begin{abstract}
Synopsis
The thermal behavior of poly(1,3-phenyl-1,4-phenyl)-4-phenyl-1,2,4-triazole has been investigated using different scanning calorimetry (DSC) and thermogravimetry (TG). Processes are studied for this thermally stable polymer that take place between 200 and $500^{\circ} \mathrm{C}$. While the polycondensation reaction product in powder from appeared to be partially crystalline, films prepared by casting from a formic acid solution appeared to be completely amorphous. A thermal treatment between $T_{g}\left(-270^{\circ} \mathrm{C}\right)$ and $T_{m}\left(-430^{\circ} \mathrm{C}\right)$ can introduce crystallinity in the films because of the polymer's ability to cold crystallize. The cold crystallization temperature $T_{c}$ seems to be dependent on the preparation history of the solid polymer phase. Thermal annealing of the films just below $T_{g}$ does not introduce crystallinity but inhibits subsequent cold crystallization at higher temperatures. Crystallization upon cooling from the crystalline melt has not been observed either. At temperatures just above the crystalline melting point the polymer starts to decompose in an exothermic reaction.
\end{abstract}

\section{INTRODUCTION}

Aromatic poly-4-phenyl-1,2,4-triazoles form a group of polymers known for their thermal and chemical stability. ${ }^{1,2}$ The polymers have been known since the early sixties and can be prepared in different ways. ${ }^{3-5}$ The most successful preparation route was developed by Holsten and Lilyquist. ${ }^{6,7}$ They developed a two-step process which involves the preparation of a prepolymer, an aromatic polyhydrazide, followed by a cyclization reaction of this prepolymer with aniline in polyphosphoric acid.

The preparation of fibers, films, and coatings of polytriazoles have been reported in the literature and in patents. ${ }^{7-9}$ Very recently the authors have successfully applied poly(1,3-phenyl-1,4-phenyl)-4-phenyl-1,2,4-triazole (TIPT) for the preparation of gas separation membranes with outstanding performance. ${ }^{10}$

Little attention has been paid in the literature to the high temperature behavior of these polytriazoles. ${ }^{7}$ In this paper, a thermal analysis study of the behavior of TIPT above $200^{\circ} \mathrm{C}$ is described. The polymer preparation is described in a previous paper ${ }^{10}$ according to the reaction scheme represented in Figure 1. Different batches of the same polymer are prepared and used for the investigations. The techniques used are differential scanning calorimetry (DSC) and thermogravimetry (TG). A discrimination will be made between the behavior of the polymer in powder and in membrane/film form and 
n<smiles>O=C(Cl)c1ccc(C(=O)Cl)cc1</smiles>

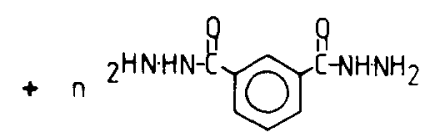

$\begin{aligned} & \text { NMP } \\ & \text { LiCl } \\ & 0^{\circ} \mathrm{C}\end{aligned} \mid-\mathrm{HCl}$ polyhydrazide

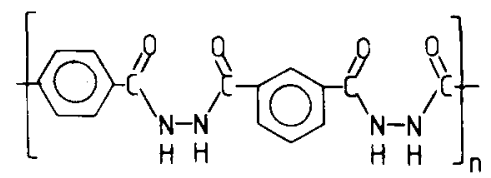<smiles>Nc1ccccc1</smiles>

polytriazole

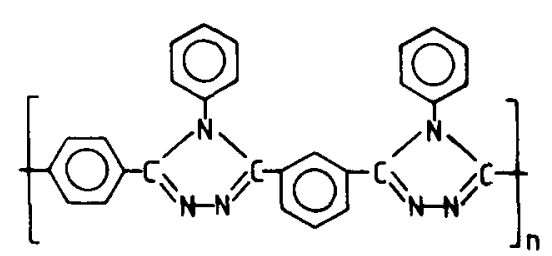

(TIPT)

Fig. 1. Reaction scheme for the polytriazole preparation.

special attention will be paid to the effect of thermal history on the DSC behavior of the films.

\section{EXPERIMENTAL}

\section{Materials}

Terephthaloyl chloride was supplied by Merck and was recrystallized from hexane prior to use.

Isophthaloyl hydrazide was prepared according to Frazer ${ }^{11}$ from isophthaloyl methyl ester and hydrazine hydrate (100\%), both supplied by Merck. The isophthaloyl hydrazide was recrystallized from water, washed with methanol and dried prior to use.

Aniline was supplied by Merck and was used as received. 
TABLE I

Reaction Conditions and Specifications of the Polytriazole TIPT Batches Used for the Experiments

\begin{tabular}{llccccc}
\hline Batch & $\begin{array}{c}T \\
\left({ }^{\circ} \mathrm{C}\right)\end{array}$ & $\begin{array}{c}t \\
(\mathrm{~h})\end{array}$ & $\begin{array}{c}\eta_{\text {inh }}{ }^{\mathrm{a}} \\
(\mathrm{dL} / \mathrm{g})\end{array}$ & $\mathrm{C} / \mathrm{N}^{\mathrm{b}}$ & $\mathrm{C} / \mathrm{H}^{\mathrm{b}}$ & $\begin{array}{l}\Delta w^{\mathrm{c}} \\
(\%)\end{array}$ \\
\hline TIPT1 & 175 & 160 & 1.2 & 4.06 & 17.63 & 1.38 \\
TIPT2 & 180 & 48 & 0.9 & 4.16 & 17.62 & 0.57 \\
TIPT3 & 172.5 & 180 & 1.3 & 4.03 & 18.30 & 0.58 \\
\hline
\end{tabular}

${ }^{\mathrm{a}}$ Determined with a $0.5 \mathrm{~g} / 100 \mathrm{~mL}$ formic acid solution at $25^{\circ} \mathrm{C}$.

${ }^{b}$ Determined using elemental analyses. Theoretical: $\mathrm{C} / \mathrm{N}=3.99$ and $\mathrm{C} / \mathrm{H}=18.71$.

${ }^{\mathrm{c}}$ Weight loss determined using thermogravimetry at $20^{\circ} \mathrm{C} / \mathrm{min}$ between 200 and $400^{\circ} \mathrm{C}$.

The solvents PPA (polyphosphoric acid), NMP, and formic acid (98\%) were supplied by Merck. The NMP was dried over $3 \AA$ molecular sieves.

\section{Polymer Preparation}

The prepolymer, poly(1,3-phenyl-1,4-phenyl)hydrazide (TIPH), was prepared according to Frazer ${ }^{11}$ from terephthaloyl chloride and isophthaloyl hydrazide using a low temperature solution polycondensation reaction in NMP. A polymer was obtained with an inherent viscosity of $1.2 \mathrm{dL} / \mathrm{g}$ measured with a $0.5 \mathrm{~g} / \mathrm{dL}$ solution in DMSO.

The polytriazole was prepared from the polyhydrazide by reacting this polymer with aniline in PPA according to Holsten and Lilyquist. ${ }^{7}$ Temperatures between 170 and $180^{\circ} \mathrm{C}$ and reaction times of 2 to 5 days were used. The viscous reaction solution was poured in an excess of water and washed in a sodium hydroxide solution till neutrality. The precipitated polymer was washed with ethanol using a Soxhlet extraction technique and afterwards dried in a stove at reduced pressure. Reaction conditions and specifications of the polymers used are given in Table I.

Using infrared analysis it can be observed for all polymers that the carbonyl stretching band at $1650 \mathrm{~cm}^{-1}$ and the $\mathrm{N}-\mathrm{H}$ band at $3350 \mathrm{~cm}^{-1}$, present in the initial polyhydrazide, have almost completely disappeared and that a $\mathrm{C}=\mathrm{N}$ band has appeared at $1580 \mathrm{~cm}^{-1}$.

\section{Film Preparation}

Polymer solutions of the polytriazole were made by dissolving $15 \%$ polymer by weight in formic acid at room temperature. The solutions were filtered over filter paper and pressed through a $5 \mu \mathrm{m}$ filter to remove inhomogeneities. Thin films were cast on a glass plate using a casting knife of $0.15 \mathrm{~mm}$ slit height. Homogeneous films were obtained by evaporating the solvent at room temperature in a nitrogen atmosphere. The films were removed from the glass plate with a little water. Asymmetric porous membranes, were obtained by immersing the cast films into a water bath followed by washing. Finally all films were dried in a vacuum oven at $150^{\circ} \mathrm{C}$ for at least $24 \mathrm{~h}$. The thickness of the homogeneous films varied between 20 and $30 \mu \mathrm{m}$. Homogeneous films pre- 
pared from batch TIPT1 were used for the investigations on gas separation reported in a previous paper. ${ }^{10}$

\section{Differential Scanning Calorimetry (DSC)}

A Perkin-Elmer DSC Differential Scanning Calorimeter in combination with a System 4 microprocessor Controller and a Model 3700 Thermal Analysis Data Station (TADS) was used for DSC measurements. Nitrogen gas was purged through the sample chambers at all times. The polymer samples were placed in aluminium sample pans which were sealed with perforated covers. Before each scan and before the weight determination the polymer sample was held isothermally at $200^{\circ} \mathrm{C}$ for $10 \mathrm{~min}$ to remove adsorbed moisture. The runs were started from $200^{\circ} \mathrm{C}$ and, unless stated differently in the text, a heating rate of $20^{\circ} \mathrm{C} / \mathrm{min}$ and a cooling rate of $320^{\circ} \mathrm{C} / \mathrm{min}$ were used.

Peak enthalpies were calculated by the TADS system, and the $T_{g}$ was defined as the midpoint temperature of the secondary transition.

The system was calibrated using indium and lead.

\section{Thermogravimetry}

A Perkin-Elmer TGS-2 Thermogravimetrical Analyzer in combination with a System 4 Microprocessor Controller and a model 3700 Thermal Analysis Data Station was used for the TG experiments. During all experiments a nitrogen atmosphere was provided by a continuous gas flow of $85 \mathrm{~mL} / \mathrm{min}$. The scan rates are equal to the ones used for the DSC experiments.

\section{RESULTS AND DISCUSSION}

In Figure 2 both the TG and the DSC curves are presented for polytriazole, in powder form, in the temperature range of 50 to $500^{\circ} \mathrm{C}$. Below $100^{\circ} \mathrm{C}$, the first weight loss is observed which corresponds to a broad endothermic peak in the DSC curve representing the loss of adsorbed water. After this first weight loss the weight seems to be constant till about $450^{\circ} \mathrm{C}$ above which tempera-

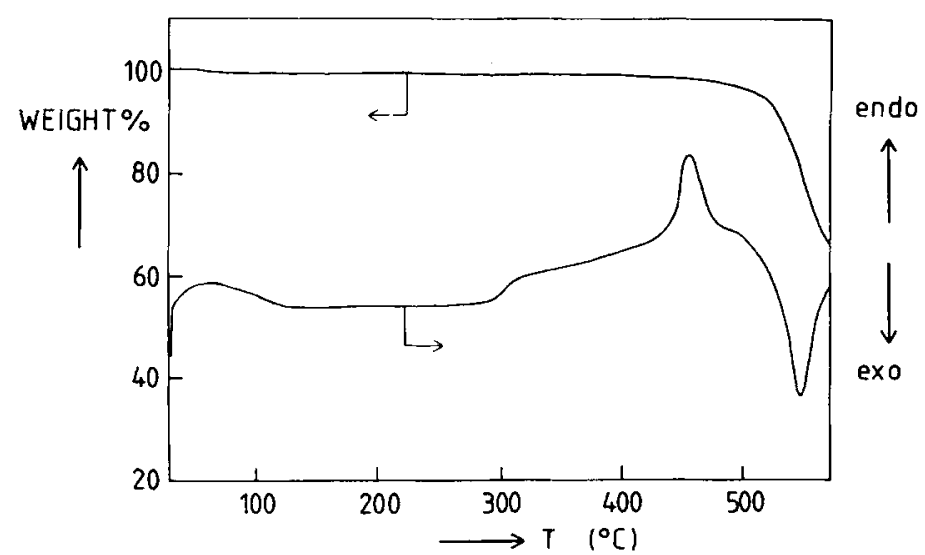

Fig. 2. TG and DSC curves for the polytriazole TIPT1 in powder form recorded at a heating rate of $20^{\circ} \mathrm{C} / \mathrm{min}$. 
ture a rapid and considerable weight loss sets in. This latter weight loss corresponds to an exothermic peak in the DSC curve and represents the thermal decomposition of the polymer.

In the temperature region in between these two weight losses the DSC curve reveals two further processes which do not seem to be coupled to simultaneous weight losses. A second order transition is observed at about $300^{\circ} \mathrm{C}$ and an endothermic peak at about $430^{\circ} \mathrm{C}$ just before the decomposition process sets in. The second order transition most probably represents the rubber-glass transition, the endothermic peak will be explained below.

Figure 3 compares the DSC curves for powder and homogeneous film in the temperature range between 240 and $460^{\circ} \mathrm{C}$. A striking difference can be observed between both morphological forms concerning the glass transition and the occurrence of an exothermic peak for the film at $360^{\circ} \mathrm{C}$.

Compared to the powder the polytriazole film possesses a much more distinct glass transition with a larger change in specific heat. Furthermore the film shows an exothermic peak at about $360^{\circ} \mathrm{C}$ which is completely absent in the powder curve. There is agreement however in the presence of an endothermic peak at about $430^{\circ} \mathrm{C}$ which can be found in both the powder and film curves. The same trend is observed for all investigated TIPT batches except for the exact temperature positions of the peaks, especially the exothermic peak. Temperatures and peak enthalpies found for the homogeneous films of the three batches are represented in Table II.

The DSC curve of the polytriazole film shows resemblarice to DSC curves of polymers which undergo cold crystallization, like for example poly(etherether-ketone). ${ }^{12}$ In this context the exothermic peak represents the cold crystallization and the endothermic peak represents the crystalline melting.

With two simple DSC experiments this hypothesis of crystallization can be verified. The first experiment is to observe the dependency of the exothermic process on the applied heating rate. It is expected that the cold crystallization, which is a kinetic process, is strongly dependent on the scanning rate. A considerable shift of the exothermic peak to higher temperatures with increas-

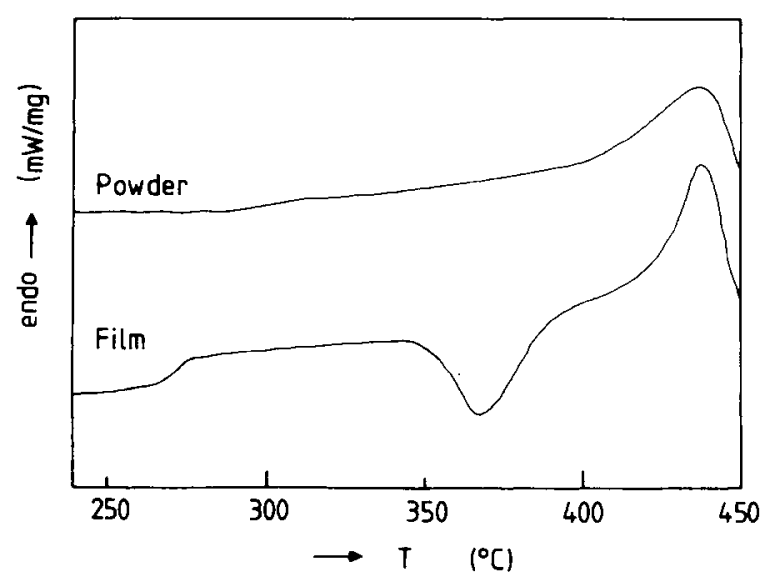

Fig. 3. DSC curves for TIPT2 in powder and in film form recorded at a heating rate of $20^{\circ} \mathrm{C} / \mathrm{min}$. 
TABLE II

Calorimetric Properties of Homogeneous Films Prepared from 'Three 'TIP'T Batches Determined Using DSC

\begin{tabular}{lcccccc}
\hline Batch & $\begin{array}{c}T_{g} \\
\left({ }^{\circ} \mathrm{C}\right)\end{array}$ & $\begin{array}{c}\Delta C_{p} \\
(\mathrm{~J} / \mathrm{gK})\end{array}$ & $\begin{array}{c}T_{\text {exoo }}{ }^{\mathrm{a}} \\
\left({ }^{\circ} \mathrm{C}\right)\end{array}$ & $\begin{array}{c}-\Delta H_{\text {exo }} \\
(\mathrm{J} / \mathrm{g})\end{array}$ & $\begin{array}{c}T_{\text {endo }}{ }^{\mathrm{b}} \\
\left({ }^{\circ} \mathrm{C}\right)\end{array}$ & $\begin{array}{c}\Delta H_{\text {endo }} \\
(\mathrm{J} / \mathrm{g})\end{array}$ \\
\hline TIPT1 & 269 & 0.155 & 333 & 26.0 & 427 & 27.7 \\
TIPT2 & 271 & 0.189 & 368 & 17.6 & 422 & 18.9 \\
TIPT3 & 268 & 0.164 & 328 & 23.9 & 422 & 23.1 \\
\hline
\end{tabular}

${ }^{a}$ Minimum temperature.

bonset temperature.

ing heating rate can indeed be observed for all batches. This shift is much stronger than is the case with the other processes which also show a slight shift to higher temperatures. For TIP'T2, besides a shift, also a decrease in the peak enthalpies is observed. In figure 4, the enthalpies of the corresponding peaks for TIPT2 films are presented showing a considerable decrease in enthalpy with increasing heating rate.

The enthalpies of the exothermic and endothermic peaks follow the same trend and are more or less of the same decreasing value. The endothermic process therefore seems to be related to the exothermic process. The step change in specific heat at $T_{g}, \Delta C_{p}$, is also presented in Figure 4 and appears not to be dependent on these heating rates.

Another experiment to investigate the possible crystallization phenomenon is to observe the glass-rubber transition, especially the magnitude of the step change in specific heat at $T_{g}$. This step change in specific heat is proportional to the mobile amorphous fraction of the polymer. ${ }^{13}$ In Figure 5 two consecutive heating runs are shown for TIPT2 powder. Just after the endothermic peak of the first run the sample is cooled very quickly to $200^{\circ} \mathrm{C}$ and run again. If the endothermic peak represents crystalline melting and no crystallization takes place upon rapid cooling then the amorphous fraction of the polymer sample should have been increased and consequently a large step change in specific heat at $T_{g}$ should be observed. This is indeed the case as Figure 5

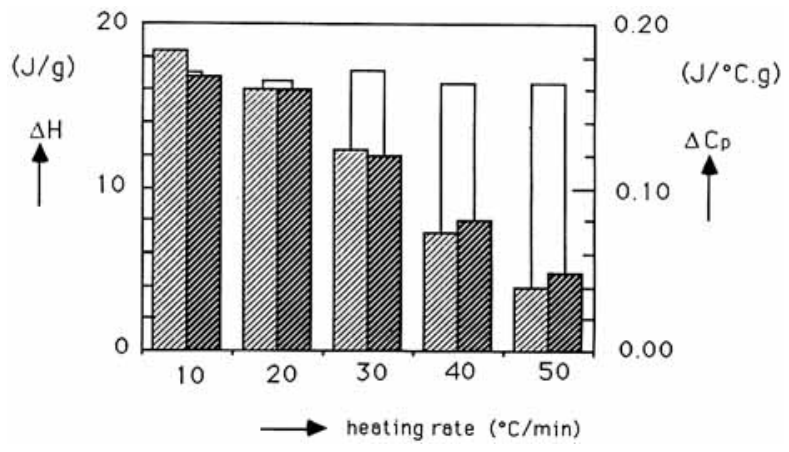

Fig. 4. Block diagram giving enthalpies of the exothermic (团) and endothermic ( $\square$ ) processes as well as the change in specific heat, $\Delta C_{p}$, at $T_{g}$ () determined for TIPT2 films using DSC at different heating rates. 


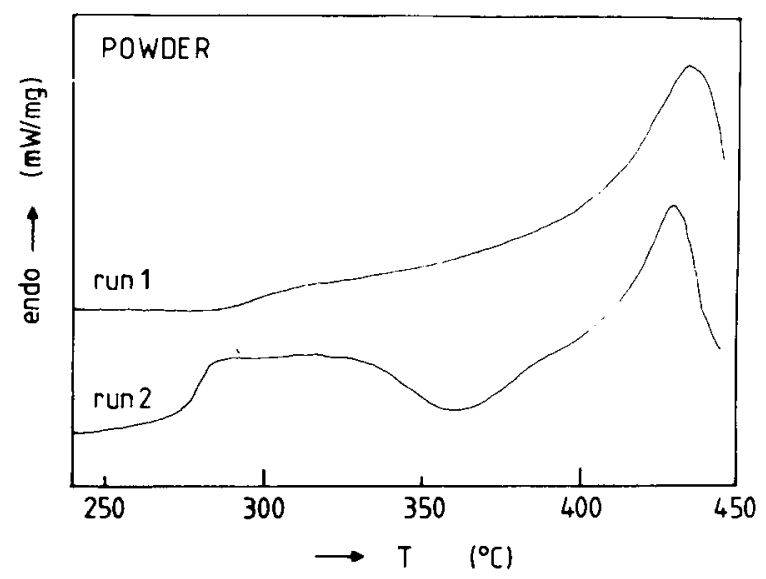

Fig. 5. DSC curves of two consecutive heating runs for TIPT2 powder.

clearly illustrates. Further it can be observed that run 2 for the powder now shows an exothermic peak at $360^{\circ} \mathrm{C}$ analogous to the film curves.

For the film sample, where run 1 is stopped just after the exothermic peak upon which the sample is cooled again, run 2 shows a smaller step change at $T_{g}$ indicating that the amorphous fraction has decreased because of the exothermic process in run 1 . Both these observations and the heating rate dependency strongly confirm the crystallization behavior. Quantitative data are collected in Table III.

These DSC observations indicate that the original powder form of the polymer is partly crystalline whereas the films seem to be amorphous. The occurrence of crystallinity in the powder samples can be confirmed using x-ray diffraction. Figure 6 shows the diffraction spectra for TIPT1 powder and film, showing qualitatively the existence of crystalline regions in the powder whereas no crystallinity can be observed for the film.

From the step change in specific heat at the glass-rubber transition, $\Delta C_{p}$, the amorphous fraction, $x_{a}$, can be calculated using the $\Delta C_{p}$ value of 0.189 $\mathrm{J} / \mathrm{gK}$ of the amorphous material. ${ }^{13}$ These results are also presented in Table III. It is disputable to calculate the fraction of crystalline material from the heat capacity jump since most semi-crystalline polymers can not simply be

TABLE III

Calorimetric Properties of TIPT2 Powder and a Homogeneous TIPT2 Film Determined Using DSC for Two Subsequent Heating Runs from 200 to $445^{\circ} \mathrm{C}$ with a Heating Rate of $20^{\circ} \mathrm{C} / \mathrm{min}$

\begin{tabular}{lccccccc}
\hline $\begin{array}{c}\text { Sample } \\
\text { (TIPT2) }\end{array}$ & Run no. & $\begin{array}{c}T_{g} \\
\left({ }^{\circ} \mathrm{C}\right)\end{array}$ & $\begin{array}{c}\Delta C_{p} \\
(\mathrm{~J} / \mathrm{gK})\end{array}$ & $\begin{array}{c}x_{a}{ }^{\mathrm{b}} \\
\left(\mathscr{g}^{\circ}\right)\end{array}$ & $\begin{array}{c}T_{c} \\
\left({ }^{\circ} \mathrm{C}\right)\end{array}$ & $\begin{array}{c}\Delta H_{\text {exo }} \\
(\mathrm{J} / \mathrm{g})\end{array}$ & $\begin{array}{c}\Delta H_{\text {endo }} \\
(\mathrm{J} / \mathrm{g})\end{array}$ \\
\hline Powder & 1 & 291 & 0.046 & 24 & - & 0.0 & 21.0 \\
& 2 & 275 & 0.189 & 100 & 361 & 9.7 & 9.7 \\
Film & $1^{\mathrm{a}}$ & 271 & 0.189 & 100 & 368 & 17.6 & - \\
& 2 & 271 & 0.059 & 31 & 348 & 0.0 & 18.1 \\
\hline
\end{tabular}

${ }^{a}$ Run until $390^{\circ} \mathrm{C}$.

${ }^{b} x_{a}$ is the fraction amorphous polymer. 


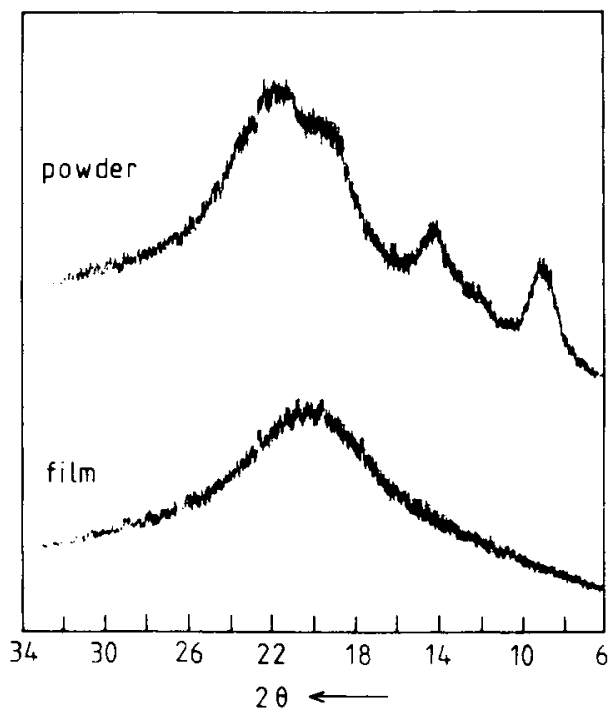

Fig. 6. X-ray diffractograms of TIPT1 powder and film.

considered to be composed of crystalline and amorphous regions. ${ }^{13}$ The socalled rigid amorphous phase, which does not exhibit a distinct change at $T_{g}$, has also to be taken into consideration. This rigid amorphous phase can form a considerable fraction in the polymer and can even be higher than the mobile amorphous fraction, which causes the jump in specific heat at $T_{g}{ }^{13}$ The crystalline fraction therefore can not be calculated from $\Delta C_{p}$ but it must be smaller than $\left(1-x_{a}\right)$.

Since melting and crystallization are reversible processes they are expected to reappear if the heating cycles are repeated. Figure 7 shows that the consecutive heating runs 2,3 , and 4 of TIPT2 powder all show both the exothermic and the endothermic peak. The surface area under the peaks,

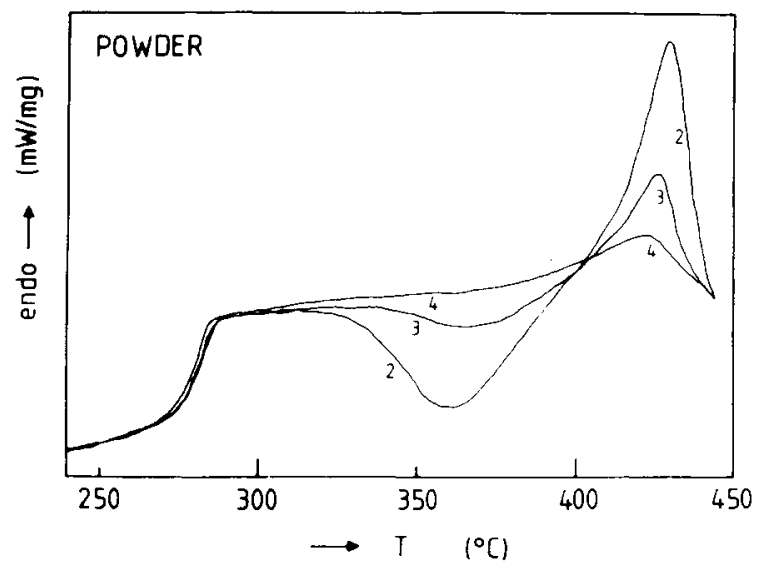

Fig. 7. DSC curves of three consecutive heating runs for TIPT2 powder: run numbers 2, 3, and 4. 


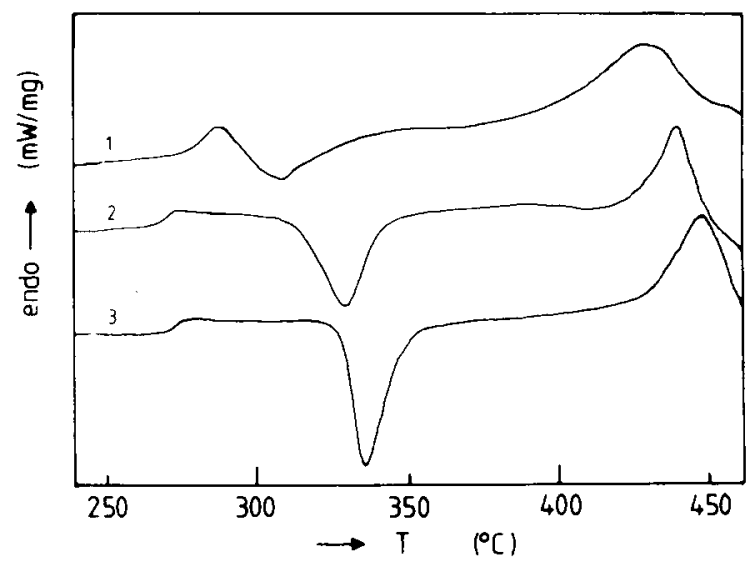

Fig. 8. DSC curves for TIPT3 samples prepared from the same formic acid solution: a powder, by pouring in water (curve 1), a porous film by immersing in water (curve 2), and a homogeneous film prepared by evaporation of solvent (curve 3).

which is proportional to the polymer fraction involved in the process, has decreased with every run. Obviously the ability to crystallize or the fraction that is able to crystallize decreases after repeated melting. The same behavior is observed for the film samples and is valid for all batches.

If we take a closer look at the endothermic peaks, e.g., in Figures 2, 3, and 7, it appears that just after the peak maximum the heat capacity drops strongly towards the exothermic side. It seems that an exothermic process is starting just after the melting process. As pointed out before, this might be the start of a decomposition process. This process might influence the kinetics of the cold crystallization in such a way that after repeated melting the fraction that crystallizes becomes less. Nevertheless this repeated melting obviously does not affect the glass-rubber transition temperature, as can be seen in Figure 7. Hence no severe degradation may be expected.

Not only the homogeneous films prepared by evaporation appear to be amorphous, also the asymmetric porous membranes and powders prepared from formic acid solutions by immersion precipitation in water show an amorphous behavior. In Figure 8 the DSC curves are presented of these differently prepared samples. The temperature position of the cold crystallization peaks seems to be dependent upon the sample preparation method. For the powder sample the crystallization immediately follows the glass-rubber transition. Also the temperature position of the melting peaks are different, perhaps indicating different crystal structures. Obviously the preparation history of the sample influences the cold crystallization process.

The fact that amorphous TIPT films have the ability to cold crystallize makes it possible to give the initially amorphous films of this polymer a certain crystallinity through a thermal treatment at a temperature above the glass transition temperature. Holsten and Lilyquist ${ }^{7}$ gave their polytriazole fibers a treatment of 1 hour at $295^{\circ} \mathrm{C}$ and analogously the polytriazole membranes (TIPT1), used in the previous paper, were given the same thermal treatment. Figure 9 shows the effect of such a thermal pretreatment on TIPT1 and TIPT2 homogeneous films. 


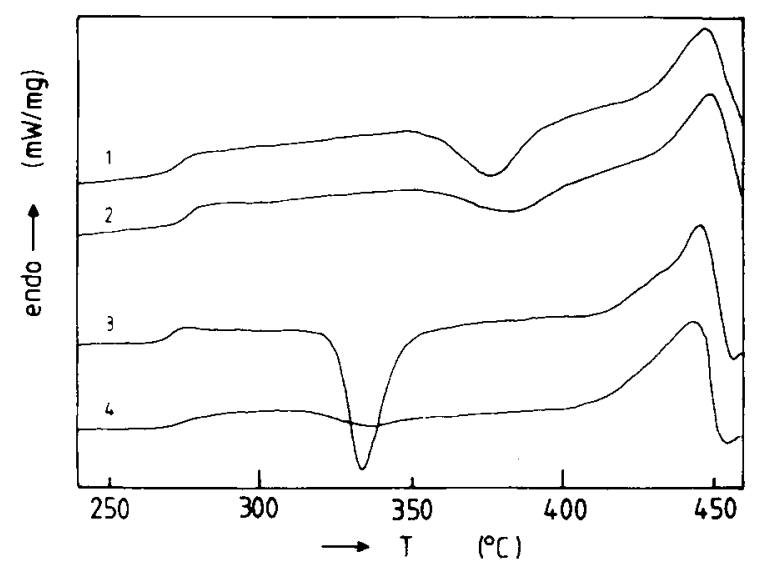

Fig. 9. DSC curves for homogeneous films of TIPT1 and TIPT2 without a thermal pretreatment (curves 3 and 1 ) and after a pretreatment of 1 hour at $295^{\circ} \mathrm{C}$ (curves 4 and 2).

In both pretreated films the exothermic peak enthalpy has decreased while the endothermic peak enthalpy has remained unchanged, indicating that the thermal pretreatment has indeed introduced some crystallinity. Because of the higher $T_{c}$ of polymer TIPT2 the same treatment has introduced relatively less crystallinity. In both cases however the $1 \mathrm{~h}$ treatment has been insufficient to render the polymers their maximal crystallinity. Longer times or higher temperatures, depending on their $T_{c}$ values, will be necessary to render the membranes their maximal crystallinity.

The influence of annealing TIPT films at a temperature below $T_{g}$ is shown in Figure 10, where DSC curves are shown for a TIPT2 film after different annealing times at $265^{\circ} \mathrm{C}$. It can be observed from this figure that a so-called specific heat hysteresis peak or a relaxation endotherm appears at the glass-rubber transition, which is also observed for other amorphous polymers, such as poly(ethylene terephthalate) and polycarbonate, upon physical

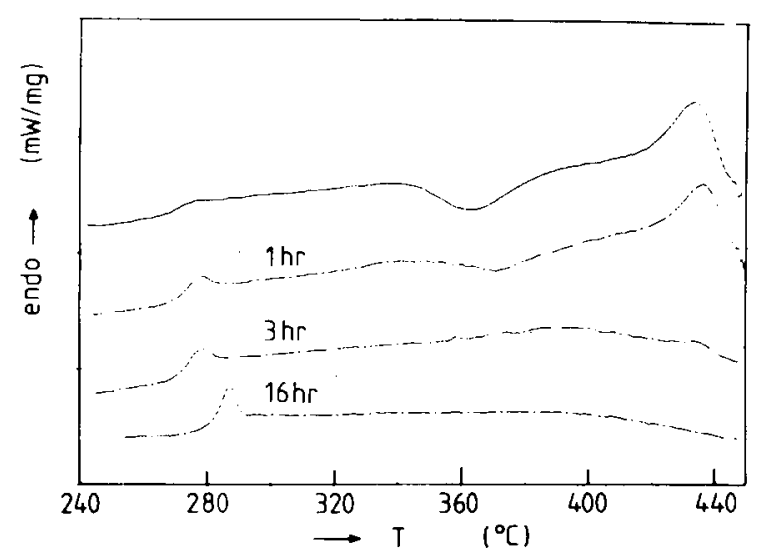

Fig. 10. DSC curves for TIPT2 films before and after annealing at $265^{\circ} \mathrm{C}$ for several annealing times. 


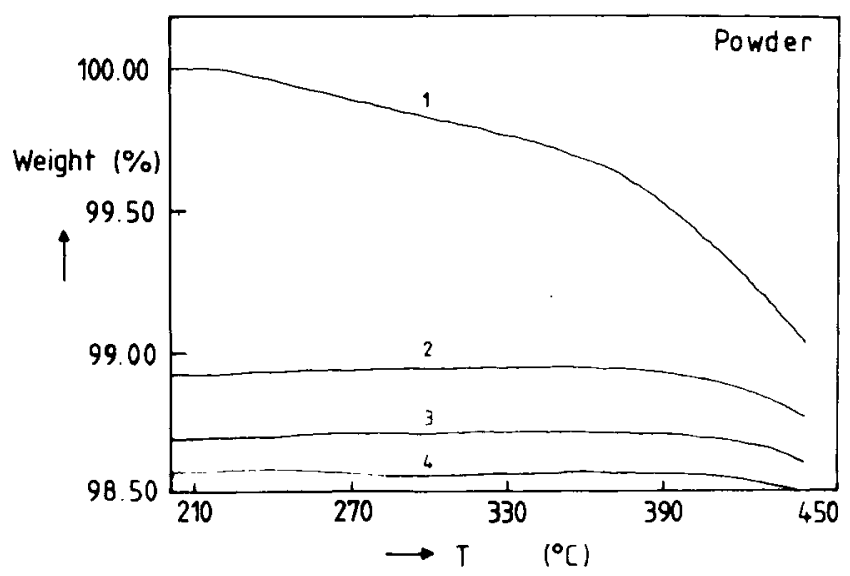

Fig. 11. TG curves of four consecutive heating runs for TIPT2 powder from 200 to $445^{\circ} \mathrm{C}$.

aging. ${ }^{14,15}$ In general, during annealing and physical aging an amorphous polymer undergoes relaxation towards thermodynamic equilibrium of the glassy state. With increased annealing time of the TIPT2 films, the endothermic peak area at $T_{g}$ and the $T_{g}$ itself increase but surprisingly the crystallization and melting endotherm resolve. After $3 \mathrm{~h}$ annealing time no crystallization and melting are observed any more. The jump in specific heat at $T_{g}$ is in the order of what is usually found for the amorphous state, so the polymer is still expected to be amorphous after annealing.

The other TIPT batches upon annealing also show an increase in the $T_{g}$ and an endothermic peak at $T_{g}$ but instead of resolving crystallization peaks only an increase in $T_{c}$ is observed. Obviously upon annealing below the $T_{g}$ the polytriazole films do not become more crystalline but are more difficult to crystallize upon subsequent heating above the $T_{g}$.

In addition to the DSC experiments described above, the same polymer treatments were also followed with thermogravimetry. Figure 11 shows the TG curves for the four consecutive heating runs of TIPT2 powder (see DSC curves in Figures 5 and 7). During run 1 a steady weight loss of about $0.5 \%$ is observed between $210^{\circ}$ and $390^{\circ} \mathrm{C}$ followed by another additional weight loss of $0.5 \%$ till the scan is stopped at $445^{\circ} \mathrm{C}$ and the sample is cooled. This weight loss process can not be observed in any heat effect during DSC runs possibly because it is too slow and steadily. After the first run no weight loss is observed in subsequent runs in the range till $400^{\circ} \mathrm{C}$ and after $400^{\circ} \mathrm{C}$ only a very small weight loss of about $0.1 \%$ is observed with every run. This last small weight loss is only the beginning of a much bigger weight loss after $445^{\circ} \mathrm{C}$ and represents possibly the beginning of the polymer decomposition. The weight losses in the temperature range between 200 and $400^{\circ} \mathrm{C}$ are presented in Table I.

The film samples show exactly the same trend in the TG curves of the consecutive heating runs, although the weight loss during the first run is in all cases a little higher than is the case for the powder. There are several possibilities to account for the processes which cause weight loss during the first heating run. It can be the loss of strictly bound solvent, water or 
(a)<smiles>CC(=O)N/N=C(/C)Nc1ccccc1</smiles>

H

(c)

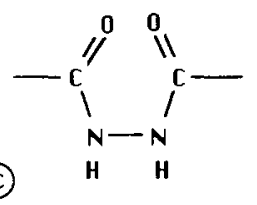

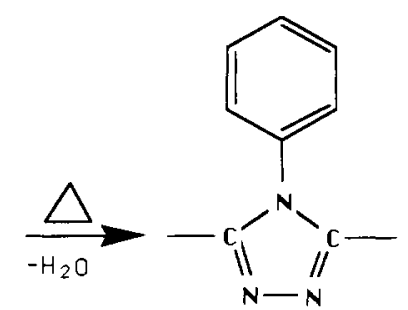

(b)

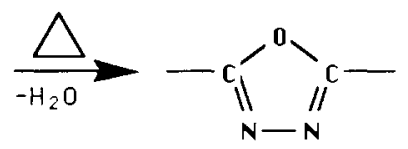

(d)

Fig. 12. Schematic representation for possible final ring closure reactions inside an incomplete polytriazole chain; a triazole cyclization ( $a$ to b) and an oxadiazole cyclization (c to d).

impurities, like reaction residues, from the polymer matrix. It could also represent a final cyclization reaction either to triazole or to oxadiazole rings (see Fig. 12) which can be expected in case the polymer preparation reaction was incomplete.

The oxadiazole ring closure reaction in the solid state is known to occur at temperatures higher than $250^{\circ} \mathrm{C} .{ }^{11,16,17}$ Especially the last groups, which are difficult to bring to a closure because of the strongly reduced mobility of the chains, are expected to do so above $300^{\circ} \mathrm{C}$. The same may be expected for the triazole cyclization. The decomposition of endgroups or other groups which might be unstable in this temperature range is another possibility. However the loss of solvent or water seems to be the most probable explanation for the weight loss starting already at $210^{\circ} \mathrm{C}$. In case of the films the higher weight loss might be caused by an additional loss of traces of formic acid from which the films have been cast.

All thermal pretreatments for homogeneous films, which were discussed above, result in a reduced weight loss in the investigated temperature range, as shown in Figure 13. During both pretreatments, either above or below $T_{g}$, the polymer film obviously undergoes a process that leads to weight loss in the temperature range between 200 and $400^{\circ} \mathrm{C}$. Despite this effect, we know from the DSC experiments that the treatment above $T_{g}$ induces crystallinity, while the treatment below $T_{g}$ does not. The possible loss of solvent or water could account for the inhibition of the cold crystallization process observed after the heat treatment below $T_{g}$. Additional analysis techniques of the volatilization products will be necessary for a better understanding of the weight loss processes that take place during these thermal treatments.

\section{CONCLUSIONS}

The polymer poly(1,3-phenyl-1,4-phenyl)-4-phenyl-1,2,4-triazole can be considared to be a semi-crystalline polymer. While the polycondensation reaction 


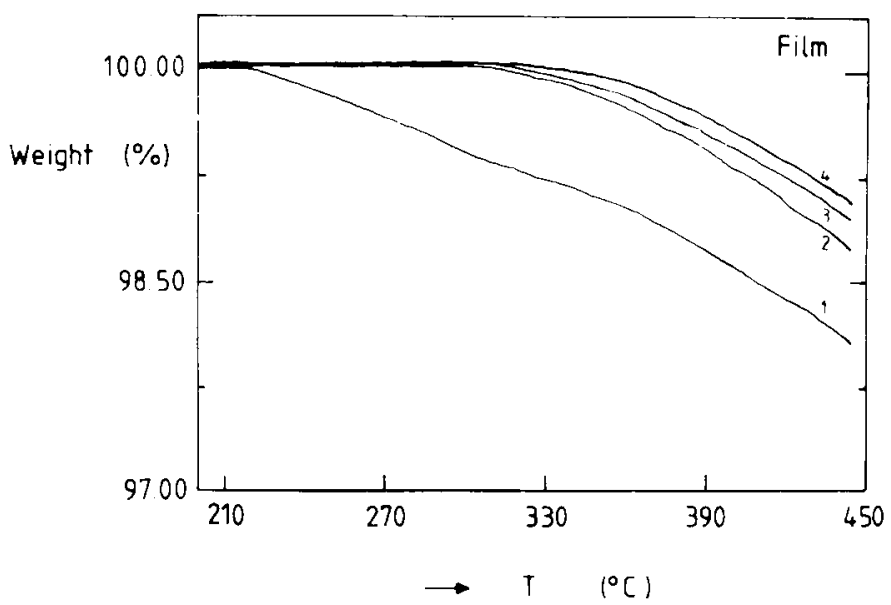

Fig. 13. TG curves for of TIPT2 film before (curve 1) and after some thermal pretreatments: $\mathrm{l} \mathrm{h}$ at $265^{\circ} \mathrm{C}$ (curve 2), $16 \mathrm{~h}$ at $265^{\circ} \mathrm{C}$ (curve 3), and $1 \mathrm{~h}$ at $295^{\circ} \mathrm{C}$ (curve 4).

product is partially crystalline, films prepared from formic acid solution, either by evaporation or immersion precipitation in water, appear to be completely amorphous. Because the polymer is able to cold crystallize, the films can be partly crystallized by a heat treatment between the glass-rubber transition temperature and the melt temperature. The cold crystallization temperature of the amorphous films was different for all batches and appeared to be influenced by the preparation history. Upon rapid cooling from above $T_{m}$ and upon annealing the films at temperatures just below the glass transition temperature for periods of $16 \mathrm{~h}$ no crystallization in the films was observed. The latter treatment however inhibits subsequent cold crystallization of the films. After repeated melting the polymer samples also loose their ability to cold crystallize. An exothermic reaction is observed just after the crystalline melting process at $430^{\circ} \mathrm{C}$ representing possibly the beginning of polymer decomposition.

Thermal pretreatments either shortly above or below $T_{g}$ are accompanied by a small weight loss of about $1 \%$, which takes place between 200 and $400^{\circ} \mathrm{C}$.

\section{References}

1. P. E. Cassidy, Thermally Stable Polymers, Dekker, New York, 1980.

2. R. J. Cotter and M. Matzner, Organic Chemistry, Vol. 13-B1, "Ring-Forming Polymerizations," Part B1, Academic, New York, 1972.

3. C. H. Abshire and C. S. Marvel, Macromol. Chem., 44 / 46, 338 (1961).

4. M. Saga and T. Shono, J. Polym. Sci. B, 4, 869 (1966).

5. P. M. Hergenrother, Macromolecules, 3(1), 10 (1970).

6. J. R. Holsten and M. R. Lilyquist, J. Polym. Sci. A, 3, 3905 (1965).

7. M. R. Lilyquist and J. R. Holsten, J. Polym. Sci. C, 19, 77 (1967).

8. M. R. Lilyquist and J. R. Holsten, Belg. Pat. 645,926 (Monsanto Co.) (1964).

9. M. R. Lilyquist, U. S. Pat. 3,318,728 (Monsanto Co.) (1967).

10. B. Gebben, M. H. V. Mulder, and C. A. Smolders, J. Membr. Sci., accepted (1989).

11. A. H. Frazer and F. T. Wallenberger, J. Polym. Sci., A, 2, 1137 (1964).

12. P. Cebe and S. Hong, Polymer, 27, 1183 (1986).

13. J. Menczel and B. Wunderlich, Polym. Prepr., 1, 225 (1986). 
14. J. Menczel and B. Wunderlich, J. Polym. Sci. Polym. Lett. Ed., 19, 261-264 (1981).

15. H. Keskkula and D. R. Paul, J. Appl. Polym. Sci., 31, 941-950 (1986).

16. B. Gebben, M. H. V. Mulder, and C. A. Smolders, J. Polym. Sci. Polym. Chem. Ed., 26, 1743 (1988).

17. B. Gebben, M. H. V. Mulder, and C. A. Smolders, J. Polym. Sci. Polym. Chem. Ed., 26, 1757 (1988).

Received July 19, 1988

Accepted November 10, 1988 